\title{
Trauma and Recovery in Wide Sargasso Sea
}

\author{
Lin Liu \\ College of Foreign Language Education, China West Normal University, Nanchong, Sichuan, China
}

Keywords: Identity Crisis, Creole, Trauma, Recovery

\begin{abstract}
Most criticisms about Jean Rhys's masterpiece, Wide Sargasso Sea, focus on its relationship with Jean Eyre, or on feminism psychoanalysis and post-colonialism. This paper tries to analyze its fiction through trauma theory with concern about Jean Rhys's special Creole origin, in order to demonstrate that the fiction is a process of Antoinette's trauma and recovery, through which Jean Rhys shows her concern for the common identity crisis of Creole people under a certain historical background.
\end{abstract}

\section{Introduction}

Charlotte Bronte's famous Jane Eyre has become a feminist classic since its publication in 1847. A century later, a Creole female writer, Jean Rhys, who shares the same cultural identity with Rochester's mad wife, Bertha, wrote a story as the prequel to Jean Eyre, which is Wide Sargasso Sea. Jean Rhys's life experiences fundamentally influenced her writing. As a Creole woman, her identity obsessed her in her writings and she devoted herself to speak out for the Creole women. With the writing of Wide Sargasso Sea, Rhys illustrates how Creole women's ambiguous identity traumatizes them under certain historic background.

\section{Identity Crisis and Trauma}

\subsection{Identity Crisis}

The Wide Sargasso Sea is set under the social reform of Jamaica in the 1930s. The Emancipation Act which declared all children slaves younger than six years old and those who were born after that date are free, came into force On August 1, 1834. The word "Creole" comes from French which borrowed from Spanish means "born outside the homeland", and Creoles in Jamaica refer to European descendants. As a result, Antoinette, a child of Creole slave-owner is trapped between the European White and the native black. It is a dilemma that the black regards the Creoles as the European colonizer while the Europeans regard them as inferior other. Antoinette's identity crisis is displayed at the very beginning of the story. Although living among the black since she was born, Antoinette is classified as a member of the ruined white class because of her family status. [I never looked at any negro. They hated us. They called us white cockroaches] (Rhys, 20). "Us" are the Creoles, and she uses the word "hate" to describe the tense relationship between the black and the Creole. Antoinette doubts her identity as neither blacks nor English, because she feels isolated by the both sides, for none of them would visit their family after her father's death. As J. Brooks Bouson points out that, [in a culture that devalues those who are different, people belonging to minority group are viewed with contempt] (Bouson, 15). Being the relative minority comparing with the black and the English, the Creoles are inevitably resented by both.

\subsection{Trauma}

The Creoles are mocked by the black as "white cockroaches" and "white nigger" before, and called "black Englishman" later. As Tia once said, [Old time white people nothing but white nigger now, and black nigger better than white nigger] (Rhys, 21). The black have kind of superiority over the Creole after the Emancipation because they are of the same economic and social status while the 
black are the majority of the population. Once the Creoles retrieve economic and social superiority by taking the side with English, the black feel threatened and take a extreme action to restore the new social order. The Coulibri fire is caused by the dissatisfaction of black towards the Mr. Mason's choice of importing coolies to replace the black servants. Although neither Antoinette nor her mother abets Mr. Mason in doing so, in the black's eyes, the Cosway family have taken their side with the English. Many black, no matter they work in Coulibri or not, take part in the arson. Antoinette's childhood is bonded with her mother and their house, Coulibri, but the fire destroys them together.

When she in the great danger and surrounded by furious black, as Antoinette sees Tia and her mother, she runs to seek protection from them. The incident is caused by the Cosway's English position, so Antoinette hopes her former friend can offer her a safe place in black community. As Antoinette believes that [for she was all that was left of my life as it had been. We had eaten the same food, slept side by side, bathed in the same river $\cdots$ I will live with Tia and I will be like her. Not to leave Coulibri] (Rhys, 38). In Antoinette's mind, she shares similarity with Tia. To be like Tia is her instinct choice of identity when facing crisis caused by identity Moreover, Coulibri is not only the house Antoinette lives in, but also implies the black culture which raises her. Unfortunately, Tia does not regard Antoinette as a member of the black. She throws a stone to Antoinette's head, which dashes Antoinette's hope to be identified as black.

Mardi Horowitz defines traumatic life events as those that cannot be assimilated with the victim's "inner schemata" of self in relation to the world (Herman, 51). Antoinette wanted to be defined as black, however, she was rejected by the black which goes contrary to her "inner schemata", and that is why she is traumatized. Since then, she shows several symptoms of trauma. Since Tia throws the stone to Antoinette, the narration of Antoinette shows the dissociation of her consciousness, [I did not see her throw it. I did not feel it either] (Rhys, 38). This unreliable narration reflect her split-off consciousness when faces this traumatic event. Herman explains this kind of situation as [the traumatized person may experience intense emotion but without clear memory of the event, or may remember everything in detail but without emotion] (Herman, 34).

\subsection{Detraumanization}

A common way to work through trauma is detraumatization. Herman suggests that, [The core experiences of psychological trauma are disempowerment and disconnection from others. Recovery, therefore, is based upon the empowerment of the survivor and the creation of new connection. Recovery can take place only within the context of relationships; it cannot occur in isolation. In her renewed connection with other people, the survivor re-creates the psychological faculties that were damaged or deformed by the traumatic experience. These faculties include the basic for trust, autonomy, initiative, competence, identity and intimacy. Just as these capabilities are originally formed in relationships with other people, they must be reformed in such relationships. ] (Herman, 133). The only way for Antoinette to recover from losing family and identity is to re-establish a close relationship with others, and the most convenient way is through marriage. Marriage has special significance to Antoinette. During her narration in childhood, it is her mother's marriage with the Englishman Mr. Mason that saves their family from poverty and misery and brings her second life and happiness. She believes her marriage with an Englishman can rescue herself from trauma just as her mother's. The Appearance of the Englishman Rochester provides Antoinette with the hope of detraumatization. Antoinette relies on Rochester to reconnect and to gain an English identity as her identity is deformed by her trauma.

Anne Whitehead suggests that the stylistic features of trauma fiction are "indirection" (Whitehead, 3) and [a dispersed or fragmented narrative voice] (Whitehead, 84). The narrative features in Wide Sargasso Sea correspond with that. In chapter one of Wide Sargasso Sea, before the traumatic experience, Antoinette is the narrator; but in chapter two, after the traumatic event, the narration is shifted to Rochester, whilenAntoinette's narration only appears occasionally.

\subsection{Retraumanization}

When misunderstanding rises in their marriage, it is impossible for Rochester to sympathize the 
awkward position of Creole that he would rather Antoinette is never a Creole. He renames her as "Bertha", a typical English name, which erases Antoinette cultural background. "Antoinette" is a variant of her mother's name "Annette", which symbols her connection with her ancestors.

In her days in the convent, after she is traumatized by her identity, Antoinette has already realized the importance of her name. She writes her name on her cross-stitch in "fire red, Antoinette Mason, nee Cosway" (Rhys, 44). Name is not only a code for Antoinette, it is also associated with her identity. So when she is deprived of the name "Antoinette" by Rochester, she is once again deprived of identity. As marriage with Rochester gets into trouble, Antoinette's hope of constructing English identity is disillusioned and she is retraumatized.

\section{Recovery}

Later when they moved to England, Rochester imprisons Antoinette in Thornfield and deprives her of discourse power, thus he can control Antoinette and charges her as mad. Antoinette becomes the "mad woman in the attic". In that way, Antoinette is exiled from the place she belongs to, confined in a foreign land, deprived of money, freedom and name. When nothing has been left for her, Antoinette only has the childhood trauma.

Herman points out that [resolution of the trauma is never final; recovery is never complete. The impact of a traumatic event contributes to reverberate throughout the survivor's lifecycle. Issues that were sufficiently resolved at one stage of recovery may be reawakened as the survivor reaches new milestones in her development. Marriage or divorce, a birth or death in the family, illness or retirement, are frequent occasions for a resurgence of traumatic memories] (Herman, 211). Her marriage with Rochester to reconnect with others doesn't work, so she has to find another way to reconnect with others.

Antoinette's choice of identity is the result of race, ethnicity as well as physical experience. Antoinette is not born as black, but the black identity is her only choice when she faces identity crisis. The black hate the Cosways and set fire to Coulibri because of the racial oppression they suffer from the English. When Antoinette is economically deprived, accused mad and encaged by Rochester, she faces the same racial oppression as the black. The marriage disillusions Antoinette's hope of English identity and makes her realizes the gap between the English and the Creoles.

During Antoinette's prison life in Thornfield, the image of red dress and fire appear in her consciousness over and over again. The red dress symbolizes the fire, and the fire is associated with Antoinette's trauma. It is the fire that brings Antoinette trauma in her childhood and leads her to deform identity, and the way of detraumatization is to form a new one in the fire. Although portrayed as illusion, Antoinette's final experience in the fire of Thornfield still reflects her inner struggle. As Antoinette says [...I turned round and saw the sky. It was red and all my life was in it] (Rhys, 155), in the fire, Antoinette reflects on all relevant connection to her past, which helps her to reestablish a connection to her childhood before trauma that enable her to detraumatize.

In that fire, Antoinette sees the two persons who influence her choice of identity. One is Tia, who arouses Antoinette hope of being identifies as black and the other is Rochester, who gives Antoinette hope of being identified as English. Antoinette makes a choice between her English husband and her black friend, as Deanna Madden explains, it is a choice between two identities, Bertha and Antoinette (Madden, 77-86). She rejects the English voice and his name for her and chooses the black voice. [...the man who hated me was calling too, Bertha! Bertha!. I saw the pool at Coblibri. Tia was there. She beckoned to me and when I was hesitates, she laughed. I heard she say, you frightened? And I heard the man's voice, Bertha! Bertha! All this I saw and heard in a fraction of a second. And the sky so red...I called 'Tia!' and jumped...] (Rhys, 155). In doing so she constructs a black identity. The Wide Sargasso Sea ends with Antoinette's awaking from her dream. Compared with Jane Eyre, its ending accords with Antoinette's former dream: Antoinette burns down Thornfield just as the black burns down Coulibri and throws herself into the fire. Although it costs her life, Antoinette successfully constructs the black identity. 


\section{Conclusions}

Rhys not simply depicts Antoinette's bewilderment of her ambiguous identity. Instead, she emphasizes how Antoinette's detraumatizes through constructing a clear identity. Anne Whitehead regards trauma fiction as a way to the [recovery of memory and the acknowledgement of the denied, the repressed and the forgotten (Whitehead, 82). She also asserts that [the desire among various cultural groups to represent or make visible specific historical instance of trauma has given rise to numerous important works of contemporary fiction] (Whitehead, 3). Antoinette's personal trauma is embedded in the larger historic background, many people suffering the same identity crisis with her. The process of Antoinette's working through trauma shows the historical choice of the Creole. Antoinette's experience is not only a course about self-fulfillment but also a course of ethnic questing. Antoinette's choice of identity is not an objective choice but a subject one in a certain era. The Wide Sargasso Sea not merely intends to change readers' stereotype about the "mad woman" Bertha in Jean Eyre, most importantly, to arouse the general concern for the Creoles people after the Emancipation Act. As a member of the Creole, Rhys tries to disclose the tremendous social change her people experienced. Not only in the Wide Sargasso Sea but also in Jean Rhys's many other works, the heroes suffering from exiling and being "the others" could be found. Authors and critics have already attached importance to many non-mainstream minorities in certain era, and it is high time to pay attention to the Creole as "the others" after the Emancipation. This paper is just an endeavor to constitute a new force in driving Caribbean works criticism towards this direction.

\section{References}

[1] Rhys, Jean. Wide Sargasso Sea. Penguin Book, Harmondsworth, 1980.

[2] J. Brooks Bouson, Quiet as It's Kept: Shame, Trauma, and Race in the Novels of Toni Morrison, State University of New York Press, Albany, 2000.

[3] Herman, Judith. Trauma and Recovery, Basic Books, New York, 1992.

[4] Anne Whitehead, Trauma Fiction, Edinburgh University Press Ltd, Edinburgh, 2004.

[5] Homi Bhabha, The Location of Culture, Routledae, London \&New York, 1994.

[6] Deanna Madden, "Wild Child, Tropical Flower, Mad Wife: Female Identity in Jean Rhys's Wide Sargasso Sea". Brown, Anne E (Eds), International Women's Writing, Greenwood Press, London, 1995. 